\title{
Topical lignocaine for pain relief in acute otitis media: results of a double-blind placebo-controlled randomised trial
}

\author{
Penny Bolt, Peter Barnett, Franz E Babl, Lisa N Sharwood
}

Emergency Department, Royal Children's Hospital, Murdoch Children's Research Institute and University of Melbourne,

Melbourne, Australia

Correspondence to: Franz E Babl, MD, MPH, FRACP, FAAP, Paediatric Emergency Physician, Clinical Associate Professor, University of Melbourne, Emergency Department, Royal Children's Hospital, Parkville, Victoria, Australia 3052; franz.babl@rch. org.au

Accepted 24 August 2007

\section{ABSTRACT}

Objective: Acute otitis media (AOM) is common in children, yet the optimal management of ear pain associated with AOM has not been well studied. We set out to determine the efficacy of topical aqueous $2 \%$ lignocaine eardrops compared with a placebo (saline) for pain relief of $\mathrm{AOM}$ in children.

Design: Double-blind, randomised, placebo-controlled trial.

Setting: Tertiary children's hospital emergency department.

Patients and interventions: Children aged between 3 and 17 years with earache and AOM without evidence of perforation were eligible. Patients were randomised to receive either $2 \%$ lignocaine or saline eardrops (placebo).

Main outcome measures: Pain scores were measured before and after ear-drop administration. Patient and physician-interpreted pain scores were measured by using the Bieri faces pain scale and visual analogue scale at 10 , 20 and 30 minutes. The primary outcome measure was reduction in patient-measured pain scores by $50 \%$ from the baseline. Secondary outcome measures were reduction in patient- measured pain scores by $25 \%$ or by at least two points. Telephone follow-up occurred after 1 day and 1 week. Analysis was by intention to treat.

Results: 63 children (31 were treated with lignocaine, 32 with placebo) aged 3 to 12 years were enrolled. The groups were demographically and clinically similar, with similar proportions having received analgesia in the preceding 4 hours. Children receiving lignocaine showed significantly lower patient-measured pain scores with a reduction by $50 \%$ from baseline at 10 minutes (RR 2.06, $95 \% \mathrm{Cl} 1.03-4.11, \mathrm{p}=0.03$ ) and 30 minutes (RR 1.44, $95 \% \mathrm{Cl} 1.07-1.93, p=0.009$ ) but not at 20 minutes (RR $1.3595 \% \mathrm{Cl} 0.88-2.06)$. The response to lignocaine treatment showed significantly lower patient-measured pain scores for $25 \%$ reduction at all time points and for two-point reduction at 10 minutes and favoured lignocaine at 20 minutes and 30 minutes without reaching statistical significance. There were no serious adverse events during the 30 minute follow-up period.

Conclusion: This study suggests that topical aqueous $2 \%$ lignocaine eardrops provide rapid relief for many young children presenting with ear pain attributed to AOM. The concurrent use of simple oral analgesia is a likely contributor to effective management of this painful childhood condition.

Acute otitis media (AOM) is a very common problem in childhood with up to $83 \%$ of children having had the condition at least once by their third birthday. ${ }^{12}$ The routine administration of antibiotics for AOM has recently come under scrutiny. ${ }^{3}$ The
2004 Cochrane review of antibiotics for AOM suggests minimal benefit from their early use, with no reduction in pain at 24 hours and only a 30\% relative reduction (95\% confidence interval 19\%$40 \%$ ) of pain seen in the antibiotic group at 2-7 days. Considering the spontaneous resolution of symptoms in $80 \%$ of children, 15 children $(95 \%$ confidence interval 11-24) would need to be treated with antibiotics to prevent one child from having some pain after two days. ${ }^{4}$ In addition, there was no effect found on recurrence of $\mathrm{AOM}$ or rates of other complications including hearing impairment. ${ }^{4}$ With this in mind, emphasis must be placed on effective symptom control for AOM.

The optimal management of ear pain associated with AOM has not been well studied, ${ }^{5}$ and no systematic reviews were available at the time of this study. A Cochrane review published in 2006 has attempted to address this issue. ${ }^{6}$ The authors concluded that of the four studies that had been conducted, only Hoberman and colleagues' study ${ }^{7}$ addressed the question of efficacy of topical agents for ear pain of otitis media, and that the data were insufficient to reach a conclusion. They asserted the need for high-quality placebo-controlled trials. Hoberman et al had reported a double-blind randomised controlled trial (RCT) where 54 participants with AOM were randomised to Auralgan (benzocaine, antipyrine and glycerine) or olive oil (placebo). All patients also received $15 \mathrm{mg} / \mathrm{kg}$ of paracetamol. Significant benefit $(25 \%$ reduction in pain) of Auralgan over the placebo was demonstrated only at 30 minutes (96\% Auralgan patients, $70 \%$ olive oil placebo, $p=0.02){ }^{7}$ However, the anaesthetic ear drops were favoured at all time points, irrespective of outcome measures used.

Lignocaine hydrochloride is a widely available local anaesthetic with rapid onset (peak effect in 2 5 minutes) and effect duration of 30-45 minutes. ${ }^{8}$ However, owing to its low lipid solubility it is poorly absorbed through the epidermis of the intact tympanic membrane (TM). ${ }^{9}$ Lignocaine is described for myringotomy-related anaesthesia with variable results, using a number of techniques to aid penetration of the drug. ${ }^{9-13}$ None of these lignocaine applications are applicable or practical for emergency department (ED) use in children; however, they do support the safety of low concentration lignocaine application to the TM. Anecdotally, topical aqueous lignocaine does provide relief for pain of AOM and is recommended by the clinical practice guidelines at the authors' institution. ${ }^{14}$ However, there are no data as to lignocaine's efficacy for this indication. 
We sought to investigate the efficacy of aqueous $2 \%$ lignocaine ear drops for relief of pain associated with AOM, in a double-blind, randomised, placebo-controlled trial. Primary outcome measure was a drop in patient-measured pain scores by $50 \%$ from the baseline. Secondary outcome measures were a drop in pain scores by $25 \%$ or by at least two points and rates of adverse events. If effective, aqueous lignocaine, an easily available and stable preparation, would be a valuable adjunct to the management of children's ear pain associated with AOM.

\section{METHODS}

\section{Setting and study population}

The study was conducted at an Australian children's hospital ED. Patients were enrolled between October 2003 and July 2004 using a convenience sample of ED presentations. Children aged between 3 and 17 years who presented to the ED with ear pain of less than 3 days' duration and evidence of AOM were identified at triage for enrollment. All triage nurses had appropriate education regarding the study. Patient enrollment was supervised by a single researcher (P Bolt). AOM was defined clinically as a TM with erythema, dullness and bulging appearance. Children were excluded from the study if they had evidence of TM perforation, a ventilation tube in situ, allergy to local anaesthetic or paracetamol, epilepsy, liver, renal or cardiac disease. Preceding oral analgesic was not a criterion for exclusion; however, details of medication use were collected. If the patient had not received analgesia in the preceding 4 hours, they were offered $15 \mathrm{mg} / \mathrm{kg}$ paracetamol. Written information about the study was given to parents and to older patients and written parental consent was obtained.

The study was approved by the hospital ethics committee and the Australian Therapeutic Goods Administration Clinical Trial Notification drugs scheme.

\section{Study design}

This study was a randomised, placebo-controlled trial. Patients and parents, those administering ear drops and those assessing ear pain were blinded to group assignment. All enrolled patients were randomly assigned to receive either $2 \%$ aqueous lignocaine or normal saline (placebo) ear drops. Both solutions were colourless and odourless, presented in identical $2 \mathrm{ml}$ dropper bottles. The drops were randomised in blocks of 10 . Three drops of study solution were instilled in the painful ear while the child lay with that ear upward for 5 minutes. If the ear pain was bilateral, the most painful ear was treated first.

Ear pain was initially measured at triage before enrollment, then during the study period at baseline (T0), ten (T10), twenty (T20) and thirty (T30) minutes by the patient and at T0 and T30 by the treating physician. Ear pain was measured using a faces pain scale for patients up to 6 years of age (Bieri Faces Pain Scale-Revised $)^{15-17}$ and a visual analogue scale (VAS; score 0-10) for use by staff and patients 7 years and upwards. Patients and parents were read written instructions and staff had been trained in the use of these pain scales. Physicians were aware of patient scores.

Further oral analgesia was offered between 10 (T10) and 30 minutes (T30) of the study period at the discretion of the treating doctor. Any analgesia given in hospital was recorded. The study ear drops were taken home with instructions prescribing three drops for ear soreness, up to 3 hourly for 24 hours only and to cease use if ear discharge occurred. Prescription of additional oral antibiotics was at the discretion of the treating physician. Follow-up phone calls were made the next day and at 1 week to determine clinical course, adverse events and medication use.

\section{Statistical analysis}

An indicative power calculation was based on comparison of groups at 30 minutes. We considered a $50 \%$ reduction in pain at each time point (T10, T20, T30) from the baseline pain score (T0) to be clinically significant and used this as the primary outcome measure. On the basis of the power calculations of the similar study by Hoberman et al, ${ }^{7}$ we estimated that $80 \%$ of children in the lignocaine group and $40 \%$ in the placebo group would attain this reduction by 30 minutes. Using these proportions (and a two group $t$ test with two-sided 0.05 significance level), a sample size of 28 per group for this study was calculated to give $80 \%$ probability (power) of producing a significant finding. We noted that in Hoberman's study, 56\% (rather than the estimated $40 \%$ ) of the placebo group patients showed $50 \%$ improvement by 30 minutes; however, it is debatable whether their placebo (olive oil) was truly inert, as commented on by the editor, DeAngelis. ${ }^{78}$ A relative-risk analysis was used to calculate the difference in proportions of patients improving in each group. Analysis was by intention to treat.

\section{RESULTS}

Over the 8-month study period, 63 children aged between 3 and 12 years of age were enrolled out of 72 patients who were identified as eligible at triage. Of those enrolled, 31 patients received lignocaine ear drops and 32 received saline (placebo). On the basis of an intention to treat analysis, two patients were retained in the study and analysed despite pain resolution subsequent to enrolment with a pain score of zero at T0. Both of these patients were in the placebo group. Telephone followup was achieved in 60 of 63 study participants (Figure 1).

Table 1 shows the two groups to be similar for age, sex, pain scores at T0, oral analgesia use before, during and after the study period.

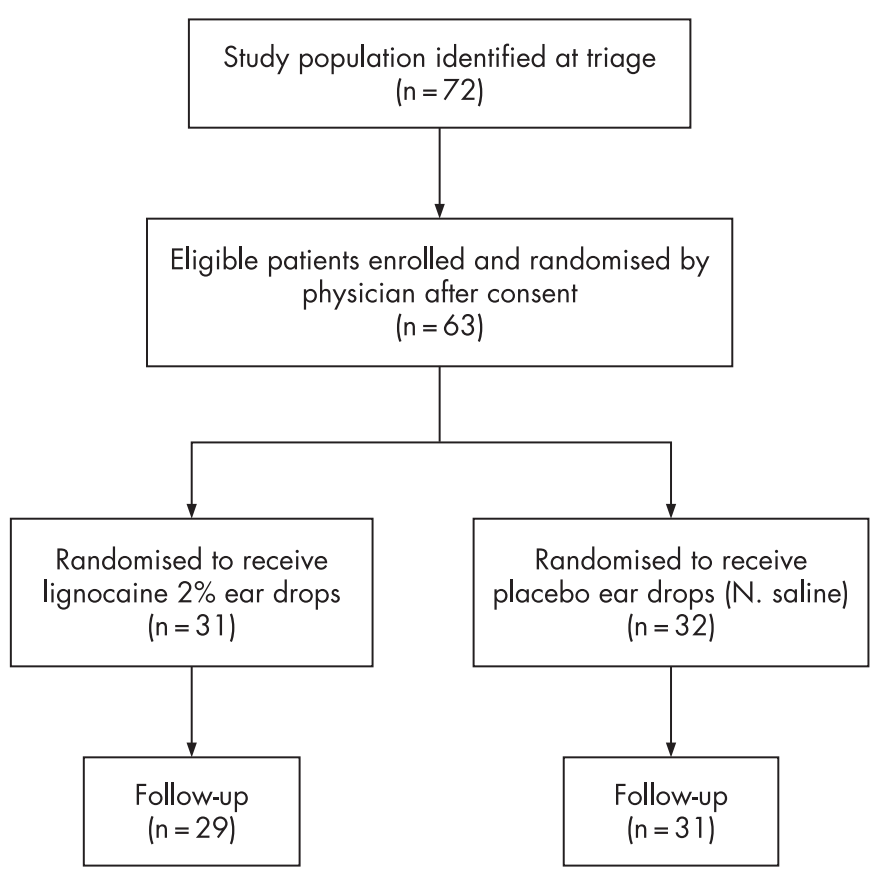

Figure 1 Study profile of lignocaine ear drops for acute otitis media. 
Table 1 Demographic data and clinical details of study groups

\begin{tabular}{lcc}
\hline Characteristic & $\begin{array}{c}\text { Lignocaine } \\
(\mathbf{n = 3 1}) \mathbf{n}(\%)\end{array}$ & $\begin{array}{c}\text { Placebo } \\
(\mathbf{n}=\mathbf{3 2}) \mathbf{n}(\%)\end{array}$ \\
\hline Mean age (years) & 5.5 & 6.2 \\
Male & $17(55)$ & $14(44)$ \\
Age $<7$ years (Bieri faces tool used) & $24(77)$ & $22(69)$ \\
Arrival time between 8pm and 8am & $23(74)$ & $23(72)$ \\
Side of pain (unilateral:bilateral) & $30: 1$ & $32: 0$ \\
Analgesia administered orally & & \\
$\quad$ No analgesia in 4 hours before T0 & $7(23)$ & $8(25)$ \\
$\quad$ Within 30 minutes before T0 & $6(19)$ & $5(16)$ \\
$\quad$ Within 4 hours before T0 & $24(77)$ & $24(75)$ \\
$\quad \begin{array}{l}\text { During study period (T10-T30) } \\
\text { After study period (before going home) }\end{array}$ & $3(23)$ & $4(10)$ \\
Pain score at T0 (mean, SD) & & $6(19)$ \\
$\quad$ Patient-measured & $6.9 \pm 2.3$ & $6.6 \pm 3.2$ \\
$\quad$ Doctor-measured & $5.7 \pm 2.4$ & $5.6 \pm 3.0$ \\
\hline
\end{tabular}

Figure 2 shows patient-measured pain scores in both groups over the course of the study at 10-minute intervals in a box and whisker plot (range, interquartile range and median). The primary outcome analysis demonstrated patient-measured pain scores to be significantly different between the two groups at T10 and T30 for reduction by $50 \%$ and at all time points for reduction by $25 \%$ from baseline (Table 2 ). $A \geqslant 2$-point reduction from baseline in patient-reported pain was significant only at T10, with trends favouring the lignocaine-treated group at later time points (Table 2). At T30, 81\% (25/31) of children in the lignocaine group and 59\% (19/32) in the placebo group reported minimal (pain score $\leqslant 2$ ) or no pain. Although doctor-measured pain scores at T30 also favoured lignocaine for reduction by $50 \%, 25 \%$ and two-point reduction, these outcomes were not statistically significant. The analysis of the primary outcome measure was repeated excluding the two patients with no pain at T0 to determine their effect, if any, on these results. Significant results favouring lignocaine for a $50 \%$ reduction of patient measured pain were still achieved at T10 (RR 1.94; 95\% confidence interval $0.98-3.8, p=0.04)$ and T30 (RR 1.35; 95\% confidence interval 1.02-1.78, $\mathrm{p}=0.02$ ).

There were no adverse events during the study period in the ED. Telephone follow-up at 1 day and 1 week was completed

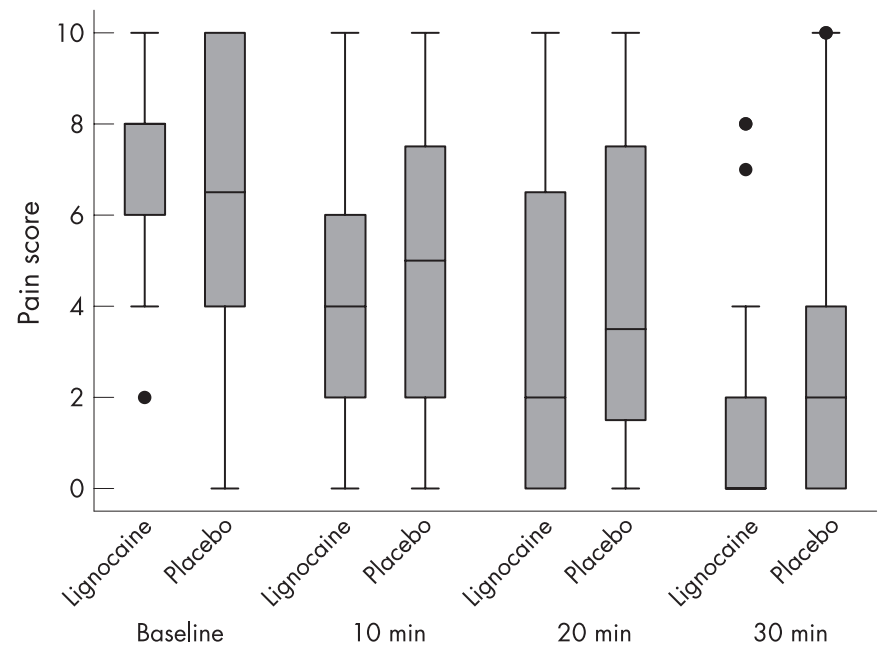

Figure 2 Patient-measured pain scores in a box and whisker plot (range, interquartile range and medians) at baseline and at 10, 20 and 30 minutes for both lignocaine and placebo groups.
Table 2 Reduction in pain scores by $50 \%, 25 \%$ and reduction in pain score by at least two points from baseline (TO) pain score

\begin{tabular}{|c|c|c|c|c|}
\hline & $\begin{array}{l}\text { Lignocaine } \\
(n=31) \\
\text { Yes/No (\%) }\end{array}$ & $\begin{array}{l}\text { Saline } \\
\text { (n=32) } \\
\text { Yes/No (\%) }\end{array}$ & $\begin{array}{l}\text { Relative Risk } \\
(95 \% \mathrm{CI})\end{array}$ & p-value \\
\hline \multicolumn{5}{|c|}{$\begin{array}{l}\text { Reduction by } 50 \% \text { in pain } \\
\text { score from T0 } \\
\text { (Yes/ No) }\end{array}$} \\
\hline \multicolumn{5}{|c|}{ Measured by patient } \\
\hline $\mathrm{T} 10$ & $16 / 15(52) *$ & $8 / 24(25)$ & $2.06(1.03-4.11)$ & 0.03 \\
\hline $\mathrm{T} 20$ & $21 / 10(68)$ & $16 / 16(50)$ & $1.35(0.88-2.06)$ & 0.15 \\
\hline $\mathrm{T} 30$ & $28 / 3(90)$ & $20 / 12(63)$ & $1.44(1.07-1.93)$ & 0.009 \\
\hline \multicolumn{5}{|c|}{ Measured by doctor } \\
\hline T30 & $26 / 5(84)$ & $21 / 11(66)$ & $1.27(0.95-1.71)$ & 0.09 \\
\hline \multicolumn{5}{|c|}{$\begin{array}{l}\text { Reduction by } 25 \% \text { in pain } \\
\text { score from T0 } \\
\text { (Yes/No) }\end{array}$} \\
\hline \multicolumn{5}{|c|}{ Measured by patient } \\
\hline $\mathrm{T} 10$ & $24 / 7(77) *$ & 14/18 (44) & $1.76(1.14-2.73)$ & 0.006 \\
\hline $\mathrm{T} 20$ & $25 / 6(81)$ & $18 / 14(56)$ & $1.43(1.01-2.03)$ & 0.03 \\
\hline $\mathrm{T} 30$ & $28 / 3(90)$ & $22 / 10(69)$ & $1.31(1.01-1.70)$ & 0.03 \\
\hline \multicolumn{5}{|c|}{ Measured by doctor } \\
\hline T30 & $28 / 3(90)$ & 25/7 (78) & $1.15(0.93-1.43)$ & 0.18 \\
\hline \multicolumn{5}{|c|}{$\begin{array}{l}\text { Two-point pain score } \\
\text { reduction from T0 } \\
\text { (Yes/No) }\end{array}$} \\
\hline \multicolumn{5}{|c|}{ Measured by patient } \\
\hline $\mathrm{T} 10$ & $23 / 8^{*}(74)$ & 15/17 (47) & $1.58(1.03-2.41)$ & 0.026 \\
\hline $\mathrm{T} 20$ & $25 / 6(81)$ & $19 / 13(59)$ & $1.35(0.97-1.89)$ & 0.06 \\
\hline $\mathrm{T} 30$ & $28 / 3(90)$ & $23 / 9(72)$ & $1.25(0.98-1.60)$ & 0.06 \\
\hline \multicolumn{5}{|c|}{ Measured by doctor } \\
\hline $\mathrm{T} 30$ & 27/4 (87) & $22 / 10(69)$ & $1.26(0.96-1.65)$ & 0.07 \\
\hline
\end{tabular}

${ }^{*}$ One lignocaine patient was missing a T10 pain score and was thus assumed to have been a failure at $\mathrm{T} 10$.

for 60 patients, with three patients uncontactable (Figure 1). Forty of these 60 (68\%) children followed up reported further ear pain the next day but only two had ear pain at 1 week. Table 3 shows the details of follow-up information. No serious side effects were evident by 1 week. Discharge from the ear was reported in five (8\%) patients within 1-3 days, and all had resolved by 1 week. However, it was unclear whether the ear discharge was wax, residual drops or pus. Only one patient with ear discharge used the study drops at home (lignocaine) and all five patients had received antibiotics by 1 week, including one patient who also received otic antibiotics. There were no episodes of tinnitus or dizziness/vertigo evident while in the department. Three patients complained of 'mild dizziness' the next day, but did not require a medical practitioner; all were in the lignocaine group, two of whom used the drops (one and three times) at home. There were no complaints of tinnitus, spinning sensation or unsteady gait on follow-up questioning.

Table 3 Follow-up details of treatment groups

\begin{tabular}{llc}
\hline Characteristic & $\begin{array}{c}\text { Lignocaine } \\
(\mathbf{n}=\mathbf{2 9}) \mathbf{n}(\%)\end{array}$ & $\begin{array}{l}\text { Placebo } \\
(\mathbf{n}=\mathbf{3 1}) \mathbf{n}(\%)\end{array}$ \\
\hline Ear pain the following day & $19(66)$ & $21(68)$ \\
Ear pain at 1 week & $1(3)$ & $1(3)$ \\
Use of study ear drops at home: once/two to & $5 / 3 / 2$ & $7 / 3 / 2$ \\
three times/four to five times & & $9(29)$ \\
Oral analgesia given in the following 24 hours & $16(55)$ & $10(32)$ \\
Systemic antibiotics by 1 week & $13(45)$ & $2(6)$ \\
Otic antibiotic drops by 1 week & $2(7)$ & $3(10)$ \\
Side effects: Ear discharge & $2(7)$ & - \\
$\quad$ Dizziness & $3(10)$ &
\end{tabular}


Systemic antibiotics were taken by $38 \%$ of the 60 patients by 1 week and four of these patients also received topical otic antibiotics by their general practitioner (two lignocaine, two saline).

Of the 54 families who took the ear drops home, about half used them in the following 24 hours (Table 3). Of note, four children received four to five doses of study drops in the next 24 hours (two lignocaine, two saline); however, none of these patients reported any discharge, ear pain at 1 week nor did they require topical otic antibiotics.

\section{DISCUSSION}

This is the first reported trial using aqueous lignocaine ear drops to relieve the pain of AOM. The results suggest this treatment to be effective in relieving the ear pain associated with AOM in young children. A significant benefit using lignocaine was demonstrated 10 minutes and 30 minutes after application, measured as a $50 \%$ reduction in pain scores from the baseline. At all time points after application, more children who received lignocaine reported a $25 \%$ reduction in pain scores from baseline than with the placebo. Although our analysis did not control for concurrent analgesic administration within 4 hours before T0 this was similar in both groups (77\% lignocaine, $75 \%$ placebo). These data suggest the concurrent administration of simple oral analgesia to be an effective component in the management of AOM associated ear pain, given the overall improvement $(50 \%$ pain reduction from baseline) seen in both groups at 30 minutes (90\% lignocaine, 63\% placebo).

Although aqueous lignocaine has previously been shown to be ineffective on un-inflamed squamous epithelium, including the external $\mathrm{TM}^{19}{ }^{19}$ the fact that an altered epithelium in other settings, such as napkin rash $^{8}$ and under occlusive dressings, ${ }^{20}$ has demonstrated increased uptake of the drug may give good reason to explain the greater effectiveness to the TM when it is inflamed.

Most children presenting with ear pain in both groups of our study demonstrated rapid improvement in their pain. After 30 minutes, the majority of children in our study reported minimal (pain score $<=2$ ) or no ear pain regardless of which ear drops were used (lignocaine 81\%, placebo 59\%). This rapid improvement regardless of intervention is consistent with findings in other studies of topical analgesic ear drops ${ }^{6} 72122$ and has been interpreted as possibly owing to the natural course of the illness, the placebo effect of being in a clinical setting or the soothing effect of any liquid on the inflamed TM. ${ }^{6}$ An interpretation of our results is the adjunctive effect of simple oral analgesia that reduces acute ear pain associated with AOM. However, it remains evident that over and above concurrent analgesic administration, pain reduction is improved using lignocaine otic drops. The Cochrane review considering antibiotic use in $\mathrm{AOM}^{4}$ also found that two-thirds of children were pain-free by 24 hours regardless of antibiotic use and that $80 \%$ had recovered spontaneously without antibiotics by $2-$ 7 days. Van Buchem et al (4,860 children) also reported over $90 \%$ spontaneous recovery of $\mathrm{AOM}$ in children within a few days without treatment. ${ }^{23}$ Thirty-eight percent of children in our study had received antibiotics by 1 week. This is substantially less than the $98 \%$ prescribing rate found by Froom et al in their 1990 International Primary Care Network report ${ }^{24}$ and recent data from our ED. ${ }^{25}$

Our findings of a relatively high rate of ear discharge (8\%) compared with data by van Buchem et $a^{23}$ are difficult to interpret. Some discharge may represent perforation of the TM;

\section{What is already known on this topic}

- Data suggest only minimal benefit of early antibiotic administration for acute otitis media.

- Data on optimal symptom management in acute otitis media are limited.

\section{What this study adds}

- Lignocaine ear drops provide rapid pain relief for children with acute otitis media.

however, it could also represent discharge of study ear drops or of dissolved wax.

The study population represents a convenience sample. An analysis of the ED database identified a further 179 patients (mean age 6.5 years) who were potentially eligible with diagnosis of AOM but were not approached for enrollment. Limitations to this study also include the variability of preceding analgesia and the additional analgesia given during the study period; however, no children received further medication until 10 minutes after the ear drops were administered. At the time, we felt that it was unethical to withhold simple analgesic therapy as the current standard of care for pain in the ED. In retrospect, it would have been better to exclude patients with prior analgesic use. The accurate measurement of pain in young children is problematic and the direct comparison between two different pain scales is potentially flawed, but the Bieri Faces Pain Scale-Revised ${ }^{16}$ has been shown to correlate with VAS. ${ }^{17}$ Physicians were aware of patient scores and might have inadvertently approximated patient scores.

\section{CONCLUSIONS}

This study suggests that aqueous 2\% lignocaine eardrops provide rapid relief for many young children presenting with ear pain attributed to AOM. The concurrent use of simple oral analgesia is a likely contributor to effective pain management.

Further studies might use longer acting or more lipid-soluble local anaesthetics. AOM will continue to be a common and distressing problem in childhood but is mostly a self-limited condition. Emphasis must therefore remain on effective and safe symptom control.

Acknowledgements: We thank patients, parents and ED staff for participating in this study. We thank Dr Susan Donath, Clinical Epidemiology and Biostatistics Unit, Murdoch Children's Research Institute for statistical advice. We acknowledge grant support from the Murdoch Children's Research Institute and the Victor Smorgon Charitable Fund, Melbourne, Australia.

Competing interests: None.

\section{REFERENCES}

1. Teele DW, Klein JO, Rosner B. Epidemiology of otitis media during the first seven years of life in children in greater Boston: a prospective, cohort study. J Infect Dis 1989;160:83-94.

2. Arnold J. Otitis media and it's Complications. In: Nelson W, Behrman R, Kliegman R, Arvin A, editors. Ne/son Textbook of Pediatrics. 15th ed. Philadelphia: Saunders, 1996:1814-24.

3. Del Mar C, Glasziou P. A child with earache. Are antibiotics the best treatment? Austr Fam Physician 2002;31:141-4.

4. Glasziou PP, Del Mar CB, Sanders SL, et al. Antibiotics for acute otitis media in children. Cochrane Database Syst Rev 2004:CD000219.

5. Berman S. Otitis media in children. N Engl J Med 1995;332:1560-5. 
6. Foxlee R, Johansson A, Wejfalk J, et al. Topical analgesia for acute otitis media. Cochrane Database Syst Rev 2006;CD005657.

7. Hoberman A, Paradise JL, Reynolds EA, et al. Efficacy of Auralgan for treating ear pain in children with acute otitis media. Arch Pediatr Adolesc Med 1997:151:675-8.

8. Catterall W, Mackie K. Local anesthetics. In: Goodman Gilman A, Hardman J, Limbird L, Molinoff P, eds. Goodman \& Gilman's The pharmacological basis of therapeutics. 9th ed. New York: McGraw-Hill, 1996:331-48.

9. Mina MM, Cheng KS. Office myringotomy and ventilation tube insertion using $10 \%$ xylocaine aerosol. J Otolaryngol 1987:16:74-6.

10. Sirimanna KS, Madden GJ, Miles S. Anaesthesia of the tympanic membrane: comparison of EMLA cream and iontophoresis. J Laryngol Otol 1990;104:195-6.

11. Timms MS, O'Malley S, Keith AO. Experience with a new topical anaesthetic in otology. Clin Otolaryngol 1988;13:485-90.

12. Derkay CS, Wadsworth JT, Darrow DH, et al. Tube placement: a prospective, randomized double-blind study. Laryngoscope 1998;108:97-101.

13. Lawhorn CD, Bower CM, Brown RE Jr, et al. Topical lidocaine for postoperative analgesia following myringotomy and tube placement. Internat J Pediatr Otorhinolaryngol 1996;35:19-24

14. Clinical Practice Guidelines Group. Clinical Practice Guidelines: Acute otitis media. In: South M, Young S, editors. url>www.rch.org.au/clinicalguide/ index.cfm?doc id = 5033. Melbourne: Royal Children's Hospital, 2006.

15. Bieri D, Reeve RA, Champion GD, et al. The Faces Pain Scale for the self-assessment of the severity of pain experienced by children: development, initial validation, and preliminary investigation for ratio scale properties. Pain 1990;41:139-50.
16. Goodenough B, Addicoat L, Champion GD, et al. Pain in 4- to 6-year-old children receiving intramuscular injections: a comparison of the Faces Pain Scale with other self-report and behavioral measures. Clin J Pain 1997;13:60-73.

17. Hicks CL, von Baeyer CL, Spafford PA, et al. The Faces Pain Scale-Revised: toward a common metric in pediatric pain measurement. Pain 2001;93:173-83.

18. DeAngelis C. Editor's note: Efficacy of Auralgan for treating ear pain in children with acute otitis media. Arch Pediatr Adolesc Med 1997;151:675-8.

19. Moller A, Grontved A. Topical anaesthesia of the normal tympanic membrane: a controlled clinical trial of different suspensions of lidocaine. J Otorhinolaryngol Relat Spec 1990; 52:168-73

20. Guzzo C, Lazarus G, Werth V. Dermatological Pharmacology. In: Goodman Gilman A, Hardman J, Limbird L, Molinoff P, Ruddon R, eds. Goodman \& Gilman's The Pharmacological basis of therapeutics. 9th ed. New York: McGraw-Hill, 1996:1593-1616.

21. Sarrell EM, Cohen HA, Kahan E. Naturopathic treatment for ear pain in children. Pediatrics 2003:111:e574-9.

22. Sarrell EM, Mandelberg A, Cohen HA. Efficacy of naturopathic extracts in the management of ear pain associated with acute otitis media. Arch Pediatr Adolesc Med 2001;155:796-9.

23. van Buchem FL, Peeters MF, van 't Hof MA. Acute otitis media: a new treatment strategy. BMJ Clin Res Ed 1985;290:1033-7.

24. Froom J, Culpepper $L, G$ rob $P$, et al. Diagnosis and antibiotic treatment of acute otitis media: report from the International Primary Care Network. BMJ 1990;300:582-6.

25. Steinmann K, Babl FE. Antibiotic prescribing rates for acute otitis media in a paediatric emergency department. J Paediatr Child Health 2006;42:204-5.

\section{Blogs from Archives of Disease in Childhood: more than just gossip}

$A D C$ has just launched Blogs from two of the journal's associate editors who would love you to contribute. Don't forget to sign up for the Blog RSS feeds so you don't miss anything.

\section{The Précis Blog}

Précis starts with the idea that any good paper can be summarised in one sentence. That sentence may sometimes be complex, and should normally leave you wanting to know more, but it will contain the core of what the paper is about. This is, by its nature, idiosyncratic, and hopefully sometimes controversial. The blog focuses on the online first part of $A D C$ :

- You might like to leave informal comments on papers, as part of a conversation between readers, or a real dialogue between authors and readers (note that comments are moderated but not routinely edited).

- You might like to comment on what has been written about your own paper.

- You might like to just read it every now and then as a way into the journal; to keep ahead of your colleagues, or your juniors, or your seniors.

The Précis blog can be found at: http://blogs.bmj.com/adc-precis

\section{The Archimedes Blog}

You'll be familiar with Archimedes, the bimonthly section of evidence-based questions and answers, and with the Archimedes blog you:

- Get to see the questions as they are being asked, and can comment on the answer you expect to see.

- Can argue about the interpretation of evidence from the published topic reports.

- Can add new information to older reports.

There are also teaching tips, bite-sized explanations of EBM concepts and links to other places where the practice of evidence-based child health can be discussed.

The Archimedes blog can be found at: http://blogs.bmj.com/adc-archimedes

lan Wacogne and Bob Phillips explain why they think this is important in an editorial in the November issue of $A D C$ (ArchDis Child 2007;92:941-2). 